\title{
Interseccionalidad de derecha e ideología de género en América Latina ${ }^{1}$
}

\section{Right-wing intersectionality and gender ideology in Latin America}

PAULO RAVECCA

Dr.

Facultad de Ciencias Sociales, Universidad de la República, Uruguay

paulo.ravecca@cienciassociales.edu.uy

Código ORCID: 0000-0002-9754-9520

MARCELA SCHENCK

Mag.

Facultad de Psicología, Universidad de la República, Uruguay

mschenck@psico.edu.uy

Código ORCID: 0000-0002-8526-3736

BRUNO FONSECA

Lic.

bfonsecalema@gmail.com

Código ORCID: 0000-0002-2327-9695

DIEGO FORTEZA

Lic.

diegoforteza@gmail.com

Código ORCID: 0000-0002-3818-6467

1 El primer boceto de esta investigación fue presentado en el Seminario "Pink tides, right turns in Latin America" (Université du Québec en Outaouais, Gatineau, Quebec), organizado por Charmain Levy y Manuel Larrabure en 2019. El proyecto se desarrolló al amparo del Grupo de Medios y Política, coordinado por Julián Durazo-Herrmann y un producto previo a este artículo fue publicado en la revista Globalizations. Agradecemos los comentarios de Sérgio Borges, Luana Melody Brasil, Julián Durazo-Herrmann, Mariana Fagundes, Yesola Kweon, Charmain Levy, Guadalupe Mar, Eduardo Monteiro, Fábio Pereira, Juan Poblete, Lia Seixas y Mara Karina Silva. 


\section{Resumen}

Este artículo explora lo que denominamos interseccionalidad de derecha (ID). Al igual que la perspectiva académica y activista de la interseccionalidad, la ID atiende a la interrelación entre distintos ejes de posicionamiento social y desigualdad. Sin embargo, el contraste entre ellas no podría ser mayor, ya que la ID no moviliza intersecciones para cuestionar el poder, sino para legitimar el statu quo y naturalizar mecanismos de opresión. El artículo muestra la centralidad del tema de la "ideología de género" en la ID. Para ello, analiza el discurso de los politólogos Agustín Laje y Christian Rosas. El estudio utiliza métodos mixtos: análisis estadístico de tuits (correlaciones y análisis de sentimientos) e interpretación de libros, videos, arengas y conferencias. Para consolidar los hallazgos, la exploración se extendió a otros/as 18 activistas y políticos/as. Concluimos que la potencia narrativa de la extrema derecha hoy radica en su carácter interseccional, en la apelación a las emociones, en el uso de la simplificación y en la reproducción obstinada y efectiva de los aspectos más conservadores del sentido común y del liberalismo.

Palabras clave: ideología de género, interseccionalidad de derecha, Twitter, América Latina, extrema derecha

\section{Abstract}

This article explores what we call right-wing intersectionality (RWI). Like the academic and activist perspective on intersectionality, RWI attends to the interrelation between different axes of social positioning and inequality. However, the contrast between them could not be greater, since RWI does not mobilize intersections to understand or question power, but rather to legitimize the status quo and naturalize mechanisms of oppression. The article shows the centrality of the theme of "gender ideology" in RWI. To do this, it analyzes the discourse of political scientists Agustín Laje and Christian Rosas. The study uses mixed methods: statistical analysis of tweets (correlations and sentiment analysis) and interpretation of books, videos, harangues and conferences. To consolidate the findings, the investigation was extended to 18 other activists and politicians. We conclude that the narrative power of the extreme right today lies in its intersectional character, in the appeal to emotions, in the use of simplification and in the obstinate and effective reproduction of the most conservative aspects of common sense and liberalism.

Keywords: gender ideology, right-wing intersectionality, Twitter, Latin America, extreme right 


\section{Introducción}

El 19 de octubre de 2019, HazteOir galardonaba a Agustín Laje y a Nicolás Márquez por su rol prominente en la "batalla cultural". Ignacio Arsuaga, presidente de la organización, explicaba que el premio era un reconocimiento a "su valentía y coraje a la hora de denunciar la ideología de género, el feminismo radical y el marxismo cultural a través de El libro negro de la nueva izquierda: Ideología de género o subversión cultural' (ACI Prensa, 2019).

La escena de estos dos argentinos siendo celebrados en España revela el carácter internacional de la extrema derecha actual, cuya visibilidad, además, se ha intensificado gracias a un uso eficaz de las redes sociales. ${ }^{2}$ El nombre del premio y los discursos de los galardonados muestran, a su vez, que este crecimiento no se agota en alcance geográfico, instrumentos o estrategias, sino que incluye las dimensiones de la retórica, la narrativa y la ideología. Tal como soñaban algunos de los politólogos autoritarios de la década de 1980 en Chile, parece que la derecha ha comprendido la relevancia política de la cultura (Ravecca, 2015, 2019).

América Latina asiste hoy a una reacción conservadora que, además de involucrar políticas públicas (Biroli y Caminotti, 2020; Pérez y Rocha-Carpiuc, 2020), disputa el terreno del sentido común y de la sensibilidad. La denuncia de la llamada ideología de género (IG) cumple en este contexto un papel medular, ya que aúna voces variopintas tales como actores religiosos, organizaciones civiles, partidos políticos y líderes de opinión independientes. Este discurso apela a ansiedades ideológicas y culturales profundas. Por ello, no sorprende que la IG sea pensada como una verdadera ofensa contra la humanidad (Cornejo-Valle y Pichardo, 2017). Los movimientos feminista y de lesbianas, gais, trans y bisexuales (LGTB+) son identificados como los perpetradores de la afrenta, y a ellos se les suman también los partidos de izquierda. La lucha contra la IG se constituye de este modo en una operación política abarcadora, polivalente y, como argumentaremos, interseccional.

2 El 5 de agosto de 2021, WikiLeaks publicó The Intolerance Network, un informe con más de 17000 documentos que revelan información sobre fuentes de financiamiento, estrategias, planes y actividades de HazteOir y CitizenGO. Dadas las sumas multimillonarias que manejan estos lobbies de extrema derecha, resulta crucial recordar que el fenómeno tiene una dimensión financiera ineludible. HazteOir fue fundada en 2001 para hacer campaña en favor de valores de derecha en España, y, en 2013, lanzó CitizenGO para expandir su trabajo más allá del mundo de habla hispana. 
Este artículo sitúa la cruzada contra la IG en lo que denominamos interseccionalidad de derecha (ID) (Ravecca et al., 2022). La interseccionalidad es un enfoque crítico de las ciencias sociales que explora el carácter multidimensional del poder y las conexiones entre raza, etnia, clase, género, diversidad sexual y otros ejes de posicionamiento social y desigualdad (Crenshaw, 1989; Viveros, 2016). La ID también actúa de forma interseccional, pero no para cuestionar la desigualdad sino para defenderla. Constituye, entonces, una suerte de interseccionalidad normativamente invertida, que legitima y protege las diversas jerarquías sociales a través de un ataque simultáneo a las diferentes teorías y movimientos que las desafían.

A continuación, ensayamos un desmantelamiento analítico de la ID y exploramos el lugar que la IG ocupa en ella. Además, mostramos el rol del ciberactivismo en la promoción de este discurso y en la producción de identidades y subjetividades de extrema derecha. El estudio se concentra en el politólogo Agustín Laje y de forma más somera incorpora a Christian Rosas. Como se apuntó, el primero es coautor de El libro negro de la nueva izquierda, además de ser un activo influencer en las redes sociales. Rosas es coautor de Ideología de género: El nuevo intento por desnaturalizar el plan eterno de Dios y tiene un rol protagónico en el movimiento Con Mis Hijos No Te Metas (CMHNTM). ${ }^{3}$ Los perfiles ligeramente disímiles de estos activistas nos remiten a dos de las estrategias principales de la extrema derecha en la actualidad: el activismo digital y la movilización de masas.

La investigación involucró métodos mixtos. Por un lado, realizamos un análisis interpretativo y en profundidad de libros, discursos, conferencias e intervenciones de los dos activistas (Carver, 2020; Geertz, 1997; Gerring, 2003). Y, por otro, analizamos sus publicaciones en la plataforma Twitter e identificamos la presencia de, y la correlación entre, términos teóricamente significativos y los sentimientos ligados a ellos. ${ }^{4} \mathrm{La}$ exploración se extendió, además, a 18 destacados/as activistas y políticos/as de Argentina, Brasil, Chile, Colombia, Costa Rica, Ecuador, México, Paraguay, Perú, República Dominicana y Uruguay.

Nuestra conclusión principal es que en la actualidad la potencia narrativa de la extrema derecha radica en su carácter interseccional, en la apelación a las emociones, en el uso de la simplificación y en la reproducción obstinada y efectiva de

3 CMHNTM es una organización antifeminista peruana surgida en 2016 para oponerse a la inclusión del enfoque de género en los planes educativos (Meneses, 2019).

4 El paisaje de la literatura sobre emociones y política es amplio y complejo (Gioscia y Wences, 2017). Somos conscientes de que la aplicación de la técnica estadística de análisis de sentimientos implica cierta reducción conceptual vis-a-vis las reflexiones teóricas disponibles. 
los aspectos más conservadores del sentido común y del liberalismo. Las características técnicas y los modelos comerciales de las redes sociales resultan favorables a estas estrategias. ${ }^{5}$

La pregunta que queda planteada es cómo responder al fenómeno. Nuestra sugerencia es que es necesario evitar la trampa de la indignación y el odio, pero, al mismo tiempo, recordando que la ID no es una empresa intelectual que habilite un debate genuino, ya que apunta a la eliminación del otro como interlocutor válido. Estos dos insights se tensan mutuamente y precisan ser sostenidos juntos. Por último, sugerimos que para lidiar con la ID las izquierdas y los movimientos emancipatorios precisan adoptar estrategias colectivas y coordinadas, también en las redes sociales.

\section{Interseccionalidad, interseccionalidad de derecha e ideología de género}

La investigación interseccional se ha consolidado como un campo de estudio amplio e internamente diverso (Crenshaw, 1989; Mügge et al., 2018; Nash, 2017; Phoenix y Pattynama, 2006; Viveros, 2016). Puesto en términos sencillos, el enfoque reconoce el carácter multidimensional de la desigualdad y consecuentemente analiza las conexiones entre raza, etnia, clase, género, diversidad sexual y otros ejes de posicionamiento social y desigualdad. La interseccionalidad ha enriquecido la interpretación académica del poder y de otros fenómenos fundamentales de la vida colectiva. De hecho, amplió la concepción misma de lo político más allá de cualquier contenedor estrecho o unidimensional (ya sea la economía, ya sea las instituciones formales). Por ello, se ha percibido también como una intervención relevante en la política de la producción de conocimiento (Ravecca, 2019).

Los debates sobre la interseccionalidad giran en torno a la separabilidad o inseparabilidad entre las dimensiones analíticamente "intersectadas" (Gunnarsson, 2017), las estrategias metodológicas adecuadas para el análisis (McCall, 2005), las múltiples geografías y genealogías del enfoque (Viveros, 2016) y el papel en él de los feminismos negros y latinoamericanos (González, 1988; Lugones, 2008;

5 Según reportó Twitter recientemente, su algoritmo favorece y amplifica las visiones asociadas con la derecha (BBC, 2021, 22 de octubre). 
Viveros, 2015, 2016), su relación con los movimientos sociales (Viveros, 2016) y su potencial cooptación neoliberal y uso como herramienta para la gestión disciplinadora de la diversidad (Puar, 2007).

Nuestra intención no es participar en las discusiones sobre interseccionalidad, sino movilizar la perspectiva que ésta ha abierto para explorar las innovaciones ideológicas y estratégicas de la extrema derecha latinoamericana. Concretamente, nuestro objetivo es mostrar que su discurso apela a "intersecciones" de un modo que resulta inspirador para un sector significativo de la ciudadanía. Reconocemos que calificar a una parte de la derecha de interseccional puede resultar chocante. Sin embargo, consideramos que nuestro proyecto honra el espíritu del enfoque, esto es, el desmantelamiento crítico de las relaciones de poder. ${ }^{6}$

El carácter interseccional de la ID radica en que abarca asuntos sociales, económicos y culturales, y en que traza vínculos entre ellos. En otras palabras, anuda conceptual y políticamente problemas distributivos y no distributivos. Así, la defensa de la propiedad privada, la resistencia contra las políticas redistributivas, la promoción de la familia tradicional y la afirmación de la diferencia "natural" entre hombres y mujeres, por nombrar algunos temas típicos, pueden conformar, y de hecho conforman, un proyecto político unificado. La ID invierte los términos normativos e ideológicos asociados a la interseccionalidad.

La ID concibe el respeto a la jerarquía como el ancla moral de la sociedad. Este principio puede sonar abstracto, pero es temáticamente flexible y sumamente operativo en sus consecuencias, ya que los enemigos quedan claramente identificados: los movimientos y las teorías que desafían a la jerarquía en cualquier ámbito. Consecuentemente, la ID practica un tipo de política que puede caracterizarse como de "nosotros contra ellos": mientras que el nosotros manufacturado por este discurso reúne atributos y perspectivas liberales, conservadoras y cristianas, el enemigo combina marxismo, feminismo y otros puntos de vista identificados como radicales. Como puede verse inmediatamente, ambos campos, nosotros y ellos, son multidimensionales (es decir, interseccionales). Además, la confrontación abarca distintos temas (desde el género hasta la economía) y espacios (tales como la academia, las redes sociales y la calle).

Bajo esta mirada, socialistas, antirracistas y feministas inventan problemas (como el patriarcado) o los exageran (como el racismo). Mientras tanto, atacan

6 Como nos indicó Mara Karina Silva, las intersecciones o las interseccionalidades pueden ser movilizadas de distintas maneras. Le agradecemos por articular de forma tan clara la ID. 
estructuras naturales y justas como la familia y el capitalismo. Esto lo hacen a través del socavamiento de principios fundamentales como la diferencia sexual, la economía de mercado y la ley y el orden. Para la extrema derecha, la izquierda hoy quiere imponer una pesadilla distópica, mezcla de libertinaje y estatismo asfixiante. Hay tanto en juego en esta lucha que la derrota no es una opción, y la indignación conservadora se hace cada vez más intensa. Volviendo a las imágenes de nosotros y ellos, el primero de los términos es representado como luchador por la libertad y la dignidad humana, mientras que el segundo es concebido como totalitario e inhumano.

En lugar de transformar la política a la Schmitt en agonística como propone, por ejemplo, Mouffe (2007), los intelectuales de la ID habitan cómodamente la lógica amigo-enemigo y le imprimen una perspectiva moralizante. En este discurso germina la posibilidad del exterminio del otro en el nombre tanto de las buenas costumbres como de la libertad. En este sentido, la ID despierta monstruos ideológicos que siempre estuvieron presentes en el liberalismo (Losurdo, 2011; Ravecca, 2019). En todo caso, el contrincante es construido como tan aberrante que pierde todos los derechos, incluso el de respirar.

Al igual que la interseccionalidad, el discurso de la ID se desplaza a lo largo del espectro separabilidad-inseparabilidad: a veces el marxismo y el feminismo se describen como aliados naturales, lo cual implica pensarlos en tanto entidades separadas; pero otras veces el discurso asume una forma más fluida, en la que el socialismo y el feminismo se perciben como una única fuerza con diferentes manifestaciones y momentos. En este contexto, la temporalidad importa y es politizada: el feminismo es visto como el nuevo marxismo (Aguayo y Rosas, 2019), como la forma en que el socialismo ha resucitado después del colapso de la Unión Soviética (Márquez y Laje, 2017).

El objetivo político de los activistas de la ID es ganar terreno donde tradicionalmente la izquierda ha tenido preponderancia: el espacio público y la cultura en sentido amplio. Por ello, resulta consistente que la ID se presente como antielitista y democrática. De hecho, sus activistas suelen describir lo que llaman "nueva izquierda" como un proyecto de intelectuales y de minorías privilegiadas. De esta forma, capitalizan el (entendible) resentimiento que parte de la población tiene hacia las élites. A su vez, la apelación a lo popular y a la gente común apunta a capitalizar la (también entendible) frustración con los dobles estándares 
del establishment progresista y la molestia con el tecnicismo desapasionado de la derecha "oficial". ${ }^{7}$

Dada la centralidad que estas expresiones de la extrema derecha le adjudican a la cultura, no sorprende la persistente reivindicación de sus intelectuales y de su rol en la guerra contra la izquierda. Nótese que esta apropiación del terreno del pensamiento no supone indiferencia hacia las emociones. Por el contrario, la cruzada contra lo que llaman corrección política -uno de los temas constantes en este discurso- funciona como oportunidad para simultáneamente articular ideas y expresar emociones intensas. Esta retórica transgresora y rebelde resulta atractiva para muchos jóvenes, especialmente hoy cuando la izquierda social y política ofrece más disonancia, fragmentación y confusión discursiva que liderazgo ideológico (Menéndez-Carrión, 2015). Al mismo tiempo, la conjunción de pasión y razón permite a la ID aferrarse a la retórica antielitista a la que hicimos referencia recién.

La denuncia de la ideología de género (IG) es una pieza clave de la ID. La noción fue originalmente acuñada desde los feminismos (Hill, 1990). La apropiación conservadora de ésta fue iniciada por el Vaticano, en sus esfuerzos para combatir el movimiento de mujeres y hacer una lectura de los derechos humanos contraria a la de las conferencias internacionales de El Cairo y Beijing (CornejoValle y Pichardo, 2017). En América Latina, uno de los primeros trabajos sobre el tema fue publicado en 1998 por la Conferencia Episcopal Peruana. Desde entonces, la IG se ha transformado en un concepto acusatorio y supuestamente revelador de que el feminismo impone la ideología donde no debe estar: el hogar y la familia. La ansiedad en torno a este peligro se ha venido intensificando desde la segunda mitad de la década de 1990, en el contexto del descontento conservador respecto de la llamada agenda de nuevos derechos (básicamente, legalización del aborto, matrimonio igualitario, adopción homoparental y derechos de las personas trans).

La noción de IG sirve también para deslegitimar la presencia del feminismo en la universidad. La extrema derecha defiende el carácter natural y sagrado de la distinción entre hombre y mujer, de la familia tradicional e, incluso, de la heterosexualidad. Complementariamente descalifica la investigación académica que da cuenta del rol de la cultura en la construcción de la identidad de género y la sexualidad (Corredor, 2019). Esta narrativa incluye a veces un ataque genérico a las

7 Para Agustín Laje, esta derecha mainstream no posee intelectuales sino solamente técnicos que, además, no se atreven a reconocer su condición de derechistas (Laje, 2018). 
humanidades y a las ciencias sociales, de las que se dice que no superan la prueba positivista de la objetividad científica y que, por tanto, son inútiles e ideológicas. Nuevamente, se percibe la multidimensionalidad del asalto, pues cubre todo lo que se percibe como pensamiento de izquierda. ${ }^{8}$

La vaguedad y la polisemia de la IG le permiten operar como fuerza discursiva centrípeta. A su alrededor orbitan lenguajes y representantes tanto del cristianismo como del cientificismo. De esta forma, la extrema derecha amplía su público, sus alianzas y avanza en el mainstreaming de las perspectivas discriminatorias. El paisaje narrativo en el que opera la IG hoy es amplio e incluye categorías como las de marxismo cultural y nueva izquierda, así como conceptos insulto tales como feminazi, corruptos y totalitarios (Aguayo y Rosas, 2019 y Márquez y Laje, 2017 son dos ejemplos contundentes de ello). Todo esto permite hacer conexiones simples y construir solidaridad y hasta una suerte de afectuosidad entre distintas causas de derecha (sobre este punto volveremos más adelante). Es a todas estas adaptaciones, mutaciones y ensamblajes temáticos conservadores que le llamamos ID.

En una coincidencia llamativa con diversas formas de teoría crítica, la ID entiende el poder como un proceso integrado que no se divide respetando las fronteras de las disciplinas académicas. Desde esa perspectiva, economía política, cultura y subjetividad no están separadas. Por ello, una vez que empezamos a desnaturalizar la jerarquía, es imprevisible dónde acabará ese proceso: sacudir la desigualdad en un nivel puede deslizarse hacia otros niveles o ámbitos. La implicación de esto es que cualquier forma de activismo que cuestione la opresión es potencialmente radical, en el sentido de Marx de ir a la raíz de los problemas. No es sorprendente, entonces, que el igualitarismo de género se vea como una amenaza al capitalismo. En otras palabras, a través de su denuncia de la IG, la ID reconoce la naturaleza igualitaria y la materialidad del feminismo. De ahí la virulencia en torno a asuntos que, paradójicamente, para muchos izquierdistas, siguen siendo triviales. Como se observará en el análisis que sigue, la extrema derecha latinoamericana ha entendido que la política no se limita a las instituciones del Estado, y eso hace que ejerza poder de un modo agudo y eficaz.

8 En Estados Unidos, donde la cuestión racial tiene un rol central en la política, hay en la actualidad una campaña furibunda de la derecha contra la critical race theory (CRT), el cuerpo de ideas en que la noción de interseccionalidad está inscripta. 


\section{Ciberactivismo de extrema derecha en América Latina: la ID en Twitter}

En diversos contextos, la extrema derecha usa de forma efectiva las nuevas tecnologías de la información y las redes sociales. El rol de WhatsApp en la elección de Bolsonaro, por ejemplo, ha causado repercusión periodística y académica (Chagas et al., Chagas, Modesto and Magalhães, 2019). Twitter ${ }^{9}$ también ha sido decisivo para que la extrema derecha pueda, al menos desde el punto de vista comunicacional, sortear el establishment conservador, al que acusa de ser demasiado blando o, incluso, cómplice de la izquierda. ${ }^{10}$ En este apartado, mostramos los modos en que la ID y su cuestionamiento a la IG se manifiestan en América Latina a través de esta plataforma.

Para simplificar la exposición, hemos ubicado los detalles técnicos del estudio en un apéndice al final del artículo. El análisis de los tuits de un individuo/ cuenta, o de un conjunto de individuos/cuentas como en el caso de la figura 1, procede a través de correlaciones entre términos teóricamente significativos, cuya intensidad está indicada por el ancho de los enlaces. Los colores, por su parte, señalan la emoción expresada en los tuits en que aparecen dichos términos. Verde $\mathrm{y}$ rojo corresponden a contenido emocional positivo y negativo respectivamente, mientras que gris indica neutralidad.

La figura 1 muestra la centralidad de la denuncia de la IG en el discurso de 17 hacedores de opinión latinoamericanos identificados/as con la extrema derecha. ${ }^{11}$ También revela que el campo enemigo, tal como lo delinea la ID, es interseccional, pues incluye tanto al feminismo como a la izquierda en general.

9 Sobre el crecimiento de Twitter y su rol como espacio de deliberación política, véase Tumasjan et al. $(2010,2011)$; sobre su papel en la reducción de las barreras para la participación, véase Anduiza et al. (2009), y sobre su utilidad para hacer campañas, coordinar protestas, así como para difundir y discutir noticias, véase Ausserhofer y Maireder (2013).

10 Hawley (2017) ha analizado su uso por la alt-right en Estados Unidos.

11 Los individuos seleccionados para el análisis fueron Jair Bolsonaro (Brasil), Olavo de Carvalho (Brasil), Agustín Laje (Argentina), Sara Winter (Brasil), Emmanuel Danann (Argentina), Fernanda Betancourt (México), Vanesa Vallejo (Colombia), Nicolás Márquez (Argentina), Carlos Leal (México), Christian Camacho (México), Juan Polanco (República Dominicana), Amparo Medina (Ecuador), Fabricio Alvarado (Costa Rica), Belén Lombardi (Argentina), Jorge Márquez (Uruguay), Bryan Albariño (Paraguay), Álvaro Dastugue (Uruguay), Pamela Pizarro (Chile), Christian Rosas (Perú) y Aarón Lara (México). La figura 1 no contempla las cuentas en portugués y, por ello, incluye solo 17 de las/los 20 activistas seleccionados. Sobre la categoría de "hacedor de opinión", véase Menéndez-Carrión (2015). 
Ligeramente a la izquierda y hacia arriba puede apreciarse el núcleo de la narrativa conservadora ("familia", "vida", "hijos", "dios") enmarcada en emociones positivas. La familia tradicional es concebida como la base de la sociedad, donde los nińos están seguros y crecen sanos y normales. La consistente imbricación de estos puntos de vista con referencias a la idea de dios revela la intimidad conceptual entre la ID y los conservadurismos católico y evangélico. La figura también indica un vínculo cargado de emociones negativas entre los términos "aborto" y "mujeres". No es de extrañar que este último esté, además, vinculado a "feministas", dado que el hostigamiento al feminismo es un rasgo central de la ID. La correlación entre "género" e "ideología" es la más fuerte, y esta última está también vinculada a "feministas" e "izquierda".

Figura 1. Correlación de toda la muestra (solo en español)

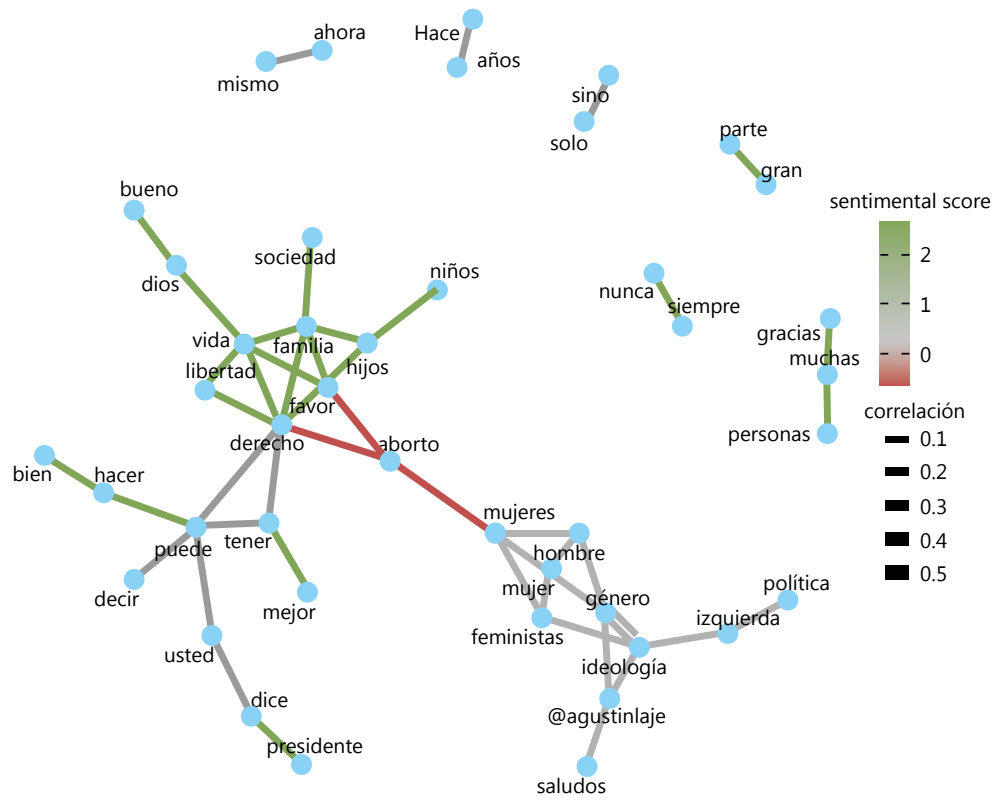

Nota: Incluye las palabras que verifican una correlación superior a 0,05 (enlaces) y alcanzan una frecuencia absoluta mínima de 100 entre todas las muestras de tuits de usuarios en español (22 498). La intensidad de la correlación se indica con el ancho de los enlaces y la puntuación media de sentimiento con el color de estos.

Fuente: Elaboración propia. 
Realizamos un análisis cualitativo de los tuits que confirma que la figura 1 expresa una narrativa llamativamente consistente que puede sintetizarse de la siguiente forma: mientras que las mujeres inteligentes y decentes rechazan a la IG, las feministas lo hacen todo mal... al protestar contra eventos sexistas, violan el derecho a la libertad de expresión; al promover el derecho al aborto, violan el sagrado derecho a la vida, y al reclamar políticas públicas sensibles al género, se convierten en una pesada carga para los contribuyentes. Se las presenta como astutas y peligrosas y a la vez como tontas y blanco perfecto para la burla. Esta y otras incoherencias no debilitan la ID, sino que parecen potenciar su habilidad para no dar tregua al enemigo.

La consistencia discursiva de la ID radica en la intencionalidad política de siempre "tirar a matar". La combinación de emoción y certidumbre resulta energizante, produce y legitima una subjetividad política de extrema derecha, y afecta los términos de la conversación pública. El interlocutor queda arrinconado con sus razones y sus dudas: la ID no habilita salida alguna porque opera por ataque e iteración, y hace que las opiniones extremas penetren lo más posible en el sentido común. Los tuits bajo análisis en este sentido son llamativamente similares tanto en tono como en contenido.

El movimiento LGTB+ también está en la mira y la "cuestión trans" en particular se ha transformado en un asunto central. El carácter inequívoco, natural y binario del sexo se reafirma una y otra vez. Esto se suma a la "protección" y promoción del matrimonio entre un ("verdadero") hombre y una ("verdadera") mujer. Mientras sectores importantes de la izquierda los consideran secundarios, la extrema derecha ha comprendido que estos temas afectan a la sociedad toda y que, además, son globales y locales al mismo tiempo. La batalla es, por ende, tanto multidimensional como trasnacional.

En la figura 1, "derecho", "vida" y "libertad" aparecen asociadas y enmarcadas en emociones positivas. Los derechos a la vida y a la libertad se conciben en oposición al aborto y al feminismo. La ID denuncia el carácter dictatorial o incluso totalitario de sus adversarios. Esta descalificación radical del otro erosiona el discurso democrático desde adentro. La categoría de democracia y los adjetivos "democrático" y "antidemocrático" son empleados como armas de una retórica furibunda donde el otro pierde toda legitimidad. De esta forma, se expanden al máximo los lugares en que liberalismo, neoliberalismo y conservadurismo pueden colaborar y resolverse en clave fascista. Esta apropiación del valor de la libertad es quizá uno de los elementos más interesantes de la ID. 
Si cuestionar las subordinaciones constituye un gesto democrático, la ID opera de forma autoritaria, naturaliza las jerarquías y quita el género, la clase, la etnia y la raza del diálogo ciudadano, todo ello en nombre de la libertad. A continuación, veremos que, cuanto más específico el nivel de análisis, más interseccional (y devastadora) se vuelve la narrativa; no obstante, incluso a este nivel agregado de más de 20000 tuits, el gráfico proporciona un mapa discursivo claro del fenómeno en estudio.

El único nombre propio mencionado en el grafo es el de Agustín Laje. Esto muestra su marcado protagonismo en el milieu de la extrema derecha latinoamericana. En general, los tuits que lo nombran expresan acuerdo con él o promueven sus libros y conferencias. Esto explica el tono neutro de las conexiones entre “@agustinlaje”, "ideología” y "género". Dada la centralidad de Laje en la ID, en el siguiente apartado nos concentramos en su discurso.

\section{Agustín Laje y la guerra digital}

Defiendo las 2 vidas, abomino de la ideología de género, reivindico nuestras gloriosas FFAA, apoyo la represión de los delincuentes y simpatizo con Bolso y Trump.

Agustín Laje (2019)

El libro negro de la nueva izquierda: Ideología de género o subversión cultural se ha convertido en una especie de manifiesto de la ID. Sus autores son elogiados y seguidos por otros/as activistas que en seminarios y entrevistas los presentan como el terror de feministas e izquierdistas. Como veíamos, es en especial uno de ellos, Agustín Laje, quien ha cobrado un protagonismo público saliente. En este apartado, analizamos su discurso utilizando distintas fuentes: el libro en cuestión, videos publicados en YouTube y su actividad en Twitter.

El libro negro de la nueva izquierda presenta debilidades significativas: no está bien escrito, no está respaldado en investigación, distorsiona hechos históricos y hace lecturas simplificadas y arbitrarias de los autores que critica (cuyos nombres están en algunos casos erróneamente redactados). ${ }^{12}$ Las fuentes que usa no son confiables, y la ausencia de argumentos solventes es acompañada de una tediosa repetición de ideas. Sin embargo, como artefacto político el libro es notable (Gol-

12 A modo de ejemplo, un detalle revelador es que cita "Foucault para principiantes" en su análisis sobre el autor. 
dentul y Saferstein, 2020). Desde nuestra propuesta analítica, lo que importa es que no solo ofrece una perspectiva de extrema derecha sobre el mundo contemporáneo, sino que además funciona como ocasión y plataforma para una infinidad de reuniones, seminarios, conversatorios, videos de exposición, entre otros. ${ }^{13}$

La forma en que el libro construye conceptualmente tanto al campo enemigo como al campo amigo es marcadamente interseccional y, por tanto, epitomiza la ID. Ataca simultáneamente al feminismo, al socialismo y al "lobby sodomita" (campo enemigo). ${ }^{14}$ Para ello, combina referencias al liberalismo, al conservadurismo, al cristianismo, al nacionalismo y a la ciencia (campo amigo). Esto supone a su vez un esfuerzo por neutralizar potenciales discrepancias entre estos últimos. Un objetivo claro del trabajo es en este sentido la producción de solidaridades y afectos de derecha. De amores reaccionarios, por así decir. ${ }^{15}$

El tema de la IG es nuevamente central. Nótese que, desde el título, se asimila la IG a la subversión cultural. Esto es significativo porque el término subversión fue empleado por las dictaduras latinoamericanas para nombrar, deshumanizar y justificar el aniquilamiento de la izquierda. En otras palabras, Laje y Márquez recogen retóricamente el legado de la guerra antisubversiva y lo actualizan en su lucha contra el feminismo. Y como la confrontación hoy ocurre en el terreno cultural, el libro procede a densificar culturalmente, es decir, a darle riqueza narrativa y simbólica, a la propuesta de la extrema derecha latinoamericana.

Laje es muy didáctico al hablar del tema:

Mucha gente nos ha dicho: "¿por qué le han puesto el libro negro de la nueva izquierda y no el libro negro de la ideología de género?”. Pues porque pensamos

13 En estas presentaciones y seminarios confluye un público diverso con presencia juvenil significativa. Esto es vívidamente ilustrado en Goldentul y Saferstein (2020): "en la jornada del 14 de marzo de 2019 en Belgrano pudimos observar perfiles diversos en la fila [...] para ingresar al auditorio: jóvenes veinteañeros identificados como liberales, adolescentes fanáticos de la cultura manga y animé, con prendedores alusivos en sus morrales, jóvenes con remeras de bandas de heavy metal nacional e internacional, grupos de adolescentes católicos o cristianos identificados con el pañuelo celeste de la campaña 'Salvemos las dos vidas', entre otras culturas juveniles" (p. 119).

14 El libro usa esta expresión para referirse a las personas LGTB+.

15 De forma gráfica, Nicolás Márquez expresó que para derrotar al enemigo se precisa formar una coalición amplia entre "liberales que crean en la vida desde la concepción, conservadores que crean que la tradición tenga que estar al servicio del progreso y nacionalistas que no confundan el amor a la patria con el amor al Estado" (Goldentul y Saferstein, 2020, p. 120). 
que, al menos políticamente hablando, los orígenes de la ideología de género están en algo que se llama nueva izquierda. (HazteOir, 2018)

Esta nueva izquierda, continúa su narrativa, tuvo un fuerte impulso en la década de 1960 y rompe con el marxismo en varias dimensiones. En el terreno de la teoría social, abandona la concepción de la cultura como superestructural; de hecho, la lucha ya no es entre clases, sino entre proyectos culturales. Además, introduce innovaciones en la filosofía de la historia y cambia completamente la estrategia revolucionaria, destruyendo el orden social y sus valores sin ofrecer un proyecto alternativo claro.

Este carácter destructivo radica en que "la izquierda es la religión laica de los resentidos sociales", los cuales mutan a lo largo del tiempo. La equiparación entre izquierda, resentimiento y destrucción es constante, pero la forma en que estos atributos se manifiestan varía en la historia: "hoy es la ideología de género, mañana puede ser otra cosa, ayer fue la lucha de clases" (Laje, 2018). En la actualidad, los proyectos de reforma cultural y transformación social han sido cooptados por un “comunismo sexualizado" (Márquez y Laje, 2017, p. 169) en que la lucha de clases marxista se mezcla con un "pansexualismo liberticida" (p. 185). En esta lectura, el feminismo y el marxismo se han amalgamado, y se han vuelto peligrosos incluso en temas que no abordan o sobre los que tradicionalmente presentan discrepancias.

La IG es, entonces, la amenaza de hoy. Laje la define como "un conjunto de ideas anticientíficas" que "desarraigan a la sexualidad humana de su naturaleza" y que la explican "monopólicamente por la cultura” (Laje, 2018). Los “ideólogos del género" promueven la fantasía de que la sexualidad es una construcción cultural. A través de esta relativización, la IG niega la naturaleza, la biología y la verdad, y las sustituye por la autopercepción de las personas. ${ }^{16} \mathrm{El}$ problema es que esto no se limita al "derecho a disfrazarse y jugar al carnaval", sino que la IG tiene "propósitos políticos autoritarios vinculados al proyecto ideológico de la nueva izquierda” (Laje, 2018). El razonamiento es descarnadamente interseccional: "no hay ideología de género sin estatismo. Es que es tan ridículo todo esto que necesita del poder del policía, del poder opresivo del Estado” (Laje, 2018). En otras

16 Laje y Márquez argumentan que ellos no están "contra los homosexuales" ni contra ningún individuo o grupo en particular, sino que su denuncia se concentra en el uso político que la izquierda hace de ellos. Sin embargo, el libro hace referencia reiterada a "sodomitas" que murieron de sida debido a su "libertinaje", y en las entrevistas mencionan sus conversaciones con homosexuales para defender las mal llamadas terapias de reorientación sexual. 
palabras, el feminismo y el "lobby LGTB” atentan no solo contra la naturaleza, sino también contra la libertad.

Para Laje, estamos al borde de una dictadura, no ya del proletariado, sino de género (Márquez y Laje, 2017, p.103). ${ }^{17}$ La acusación al feminismo de autoritarismo termina en una equiparación con el nazismo (p. 103). Las feministas son calificadas de feminazis. Pero el feminismo no es identificado solo como el promotor de un orden opresivo. También, y contradictoriamente, es asociado al libertinaje y a la anarquía. Algo similar ocurre con los derechos humanos. Estos son interpretados como un negocio o confabulación de los organismos internacionales y de la nueva izquierda y, sin embargo, Laje en particular y la ID en general, se apropian del lenguaje de los derechos. ${ }^{18}$ Estas interpretaciones contradictorias presentan una constante: el feminismo es más violento y peligroso que el machismo.

La academia y las universidades no quedan bien paradas en esta narración: por un lado, porque, al generar ideas anticientíficas y peligrosas, están traicionando su propósito más fundamental; y por otro, porque ponen de manifiesto su carácter elitista y antipopular. La IG no es un producto de las masas sociales, sino un artefacto cultural diseñado para persuadirlas y confundirlas (Laje, 2018). En este sentido, destaca nuevamente el rol político que la ID le otorga a la cultura y al conocimiento. Laje señala que, cuando las ideas "se hacen mainstream", tienen efectos poderosos, sobre todo en la vida de los más vulnerables: jóvenes y nińos. La inoculación de la IG en las mentes de los estudiantes de todas las edades es una de las principales preocupaciones de los movimientos conservadores. Los educadores se ven con sospecha y la educación como campo de batalla ideológica. ${ }^{19}$

17 La idea de la dictadura feminista es significativa especialmente en América Latina, donde hay una historia reciente de rupturas democráticas y de violaciones masivas a los derechos humanos. Curiosamente, la ID suele negar, minimizar o, incluso, justificar estas violaciones. La defensa de las dictaduras de derecha latinoamericana (que, a diferencia de la de género, sí existieron) es una constante.

18 Investigaciones recientes en RRII, por ejemplo, revelan que los colectivos conservadores utilizan con efectividad la noción de derechos de la familia. Los grupos antifeministas han aprendido de sus contrincantes feministas cómo navegar organizaciones complejas como la ONU (Cupać y Ebetürk, 2020).

19 Un ejemplo de este fenómeno es el movimiento Escuelas sin Partido de Brasil. Las figuras de Antonio Gramsci, a quien Márquez y Laje (2017) le dedica un apartado íntegro, y de Paulo Freire (calificado de agente marxista en el libro) y sus conceptos de hegemonía y de educación popular, son mencionados con frecuencia para mostrar el modus operandi de la izquierda y su penetración en el mundo académico y en la cultura popular. 
Laje suele denunciar a las instituciones educativas y a los medios de comunicación por su complicidad con el feminismo y con la IG. En este contexto, las redes sociales adquieren un rol invaluable. Estas ofrecen los escasos espacios en que es posible resistir la corrección política que constriñe, incluso, al discurso de la derecha oficial. Por ello, según Laje, sus seguidores y aliados deben practicar una "una guerra de guerrillas" y ser "partisanos de nuestro siglo [...] nuestra selva es la red social hoy en día, donde lanzamos como francotiradores ataques y municiones inorgánicas" (Laje, 2018). Esta batalla cultural es librada mediante mensajes breves, emociones intensas e imágenes y temas a menudo grotescos. Por ejemplo, según las descripciones de numerosos videos de YouTube, Laje rutinariamente "barre el piso" con las feministas o las "destruye", "destroza" y "humilla".

Con más de medio millón de seguidores/as ${ }^{20}$, Laje ha entendido muy bien el potencial político de Twitter. Como se observa en la figura 2, muchos de sus tuits se destinan a promocionar sus actividades (conferencias, debates, publicaciones). Estos aparecen en tonalidades positivas. Asimismo, el grafo no arroja sorpresas y confirma el énfasis antifeminista de este destacado representante de la extrema derecha regional. La correlación más fuerte se observa entre "género" e "ideología", términos a su vez conectados a "feministas" y "feminismo". Las palabras que refieren de un modo u otro al feminismo están enmarcadas en emociones negativas, en particular "aborto" y "derecho". Al igual que en la figura 1, observamos que la denuncia de la IG funciona hoy como el vocabulario más prominente para atacar al feminismo, concibiéndolo como la "nueva izquierda". Este vocabulario conservador es polivalente e interseccional.

Las redes sociales se han transformado en un ámbito central para la extrema derecha argentina, pero ésta no carece de expresiones electorales. Recientemente, se celebraron elecciones legislativas y la tercera fuerza más votada en la capital fue La Libertad Avanza. Se trata de una coalición de extrema derecha formalmente creada en julio de 2021 y liderada por Javier Milei, un economista neoliberal que se opone a lo que llama feminismo radical y tiene perspectivas antidemocráticas y violentas. ${ }^{21}$ Milei despliega una performatividad asociada a lo rebelde, tiene amplia presencia mediática y es simpatizante de Vox, Trump y Bolsonaro, con quienes afirma compartir la lucha contra el comunismo (DW, 2021). Agustín Laje lo elogió por su postura antisistema y de "derecha populista", y le expresó su apoyo públicamente: "Yo no escondo mis preferencias políticas, no me hago

20518227 a diciembre de 2021.

21 Ha declarado, por ejemplo, que con los "zurdos de mierda" no se debe negociar (El Peluca Milei, 2021). 
Figura 2. Correlación de los tuits de Agustín Laje

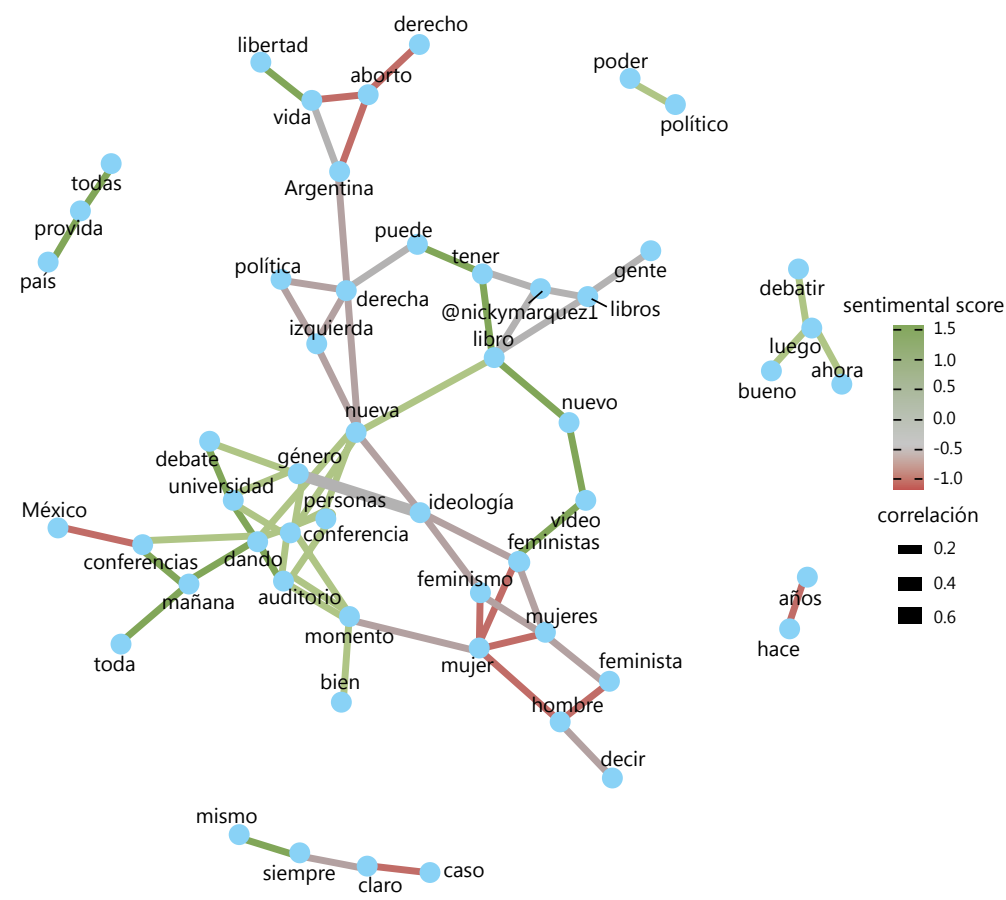

Nota: Incluye las palabras que verifican conjuntamente una correlación superior a 0,15 (enlaces) y alcanzan una frecuencia absoluta mínima de 20 entre los 970 tuits (24/03/2019-26/02/2020) analizados de Agustín Laje. El grado de correlación se indica con el ancho de los enlaces y la puntuación media del sentimiento se indica con su color.

Fuente: Elaboración propia.

el neutral [...] estoy buscando que mis seguidores se decidan a votar todos en ciudad de Buenos Aires por Javier Milei” (Laje, 2021). Ahora miembro de la Cámara de Diputados, Milei es un ejemplo de cómo el activismo cultural de la extrema derecha (y más precisamente de lo que llamamos ID) puede traducirse exitosamente en política electoral. 


\section{Christian Rosas: Dios tomó las calles}

Teniendo en cuenta sólo sus seguidores en Twitter, ${ }^{22}$ Christian Rosas difícilmente puede ser considerado un influencer. Sin embargo, este politólogo que se define a sí mismo como cristiano y conservador es el portavoz de CMHNTM en Perú. El grupo inició oficialmente su actividad en Lima el 29 de noviembre de 2016, en protesta contra la inclusión de la perspectiva de género en las políticas desarrolladas por el Ministerio de Educación (Gallego y Romero, 2019). Menos de dos años después se multiplicaba en otros países y proyectaba acciones intercontinentales.

El libro Ideología de género: El nuevo intento por desnaturalizar el plan eterno de Dios, del que como comentamos antes Rosas es coautor, define a CMHNTM como un movimiento ciudadano y de padres de familia que busca proteger a los niños de la IG. Según relata, este "peligro" fue advertido a tiempo, pues resultó "evidente" que la IG produciría "confusión sexual en los nińos", "nociva permisividad moral" y una "enseñanza de antivalores como el mal llamado 'derecho' de las mujeres al aborto". Contra tal "intento de colonización ideológica, muchos padres se pusieron de pie para reclamar su legítimo derecho de educar a sus hijos según sus propios valores" (Aguayo y Rosas, 2019, p. 128). La referencia a la colonización es importante porque toca una fibra sensible en el discurso político latinoamericano. Este reclamo de autonomía política y cultural replica una operación conservadora que se observa en distintas partes con modulaciones locales. Por ejemplo, en Uganda, las Iglesias evangélicas han declarado la homosexualidad como antiafricana (unafrican) y en Europa del Este la ultraderecha protesta contra el imperialismo cultural de la Unión Europea (UE).

El objetivo de CMHNTM es claro: "erradicar por completo todo atisbo de ideología de género en los organismos estatales" (Aguayo y Rosas, 2019, p. 130). Para ello, apela a estrategias típicamente utilizadas por los partidos y movimientos de izquierda (Eaton, 2014) como, por ejemplo, el despliegue de una fuerte presencia en las calles, marchas y protestas con gigantografías. La articulación con el fujimorismo y otras fuerzas de derecha se tradujo en victorias en el terreno de la política pública. Grupos similares se han formado en Argentina, Bolivia, Chile, Colombia, Ecuador, El Salvador, España, Estados Unidos, Francia, Honduras, Paraguay, Polonia, República Dominicana y Uruguay, en una onda expansiva que continúa creciendo.

2 4523, a diciembre de 2021. 
Agustín Laje ha alabado CMHNTM señalando que este movimiento evangélico "ha frenado la ideología de género". Según él, es hora de que la Iglesia católica "se ponga también al frente de esto". Laje se pregunta cómo, dada la complicidad de los medios de comunicación con la nueva izquierda, es posible influir en los políticos. La respuesta no radica solo en el ciberactivismo, sino también en salir "a las calles a marchar, como se hizo en muchos lugares" (Laje, 2018). La presidencia de Bolsonaro en un país tan importante como Brasil y la consolidación de organizaciones similares como Escuelas sin Partido (activa desde 2004) parecen, además, haber configurado un escenario propicio para la movilización conservadora a escala regional.

La figura 3 ilustra el discurso de Rosas en Twitter. Nuevamente, son pocas las sorpresas. Las palabras "mujer" y "hombre" están vinculadas en tono positivo y están conectadas a su vez con "vida", "familia" y "matrimonio". Los enlaces con "orientación" tienen un tono neutro, pero esto no debe confundirse con una interpretación positiva de la diversidad sexual. De hecho, en sus tuits Rosas defiende la reorientación sexual, es decir, las mal llamadas terapias de conversión para "curar" la homosexualidad (Mendos, 2020). ${ }^{23}$ También afirma que las personas LGTB+ tienen "identidades falsas" (2018).

Como en el caso anterior, el discurso presenta acentos locales. Rosas (2012) elogia al controvertido expresidente Alberto Fujimori por derrotar al "terrorismo" (de izquierda) con "la menor cantidad de violaciones" a los derechos humanos posible. Su discurso es claramente interseccional, ya que vincula el "terrorismo comunista" con el derecho al aborto. Aparece otra vez el argumento de que la guerrilla de antańo se ha transformado en el feminismo de hoy.

Para Rosas (2011), la "defensa de la vida del no nacido" es una cuestión de derechos humanos; no de orden religioso sino moral. Así, el lenguaje de los derechos es re-alineado con los valores religiosos. En esta lógica, la IG se opone tanto a dios como al Estado de derecho.

23 Nótese, además, que, una vez corregido el sesgo del diccionario, estos enlaces adquieren color rojo y, por tanto, denotan emociones negativas (véase anexo). Laje también defiende las mal llamadas terapias de conversión. Estas han cobrado la vida de miles de personas en todo el mundo. Uno de los aspectos más dolorosos de los movimientos antihomosexualidad es la instrumentalización de gais, lesbianas y trans en su política de comunicación. Sobre este fenómeno en Estados Unidos, véase el reciente documental Pray Away (Stolakis, 2020). 
Los tuits de Rosas tienen una redacción desordenada, pero sus implicaciones políticas son claras. Estos apelan consistentemente al cristianismo y a Jesús; conciben el matrimonio heterosexual como el único posible y válido; agravian a las ONG feministas (como el Centro para la Promoción y Defensa de los Derechos Sexuales y Reproductivos [Promsex]), y justifican el autoritarismo de derecha. En las últimas elecciones en que resultó electo presidente Pedro Castillo, Rosas apoyó a Keiko Fujimori.

Figura 3. Correlación de los tuits de Christian Rosas

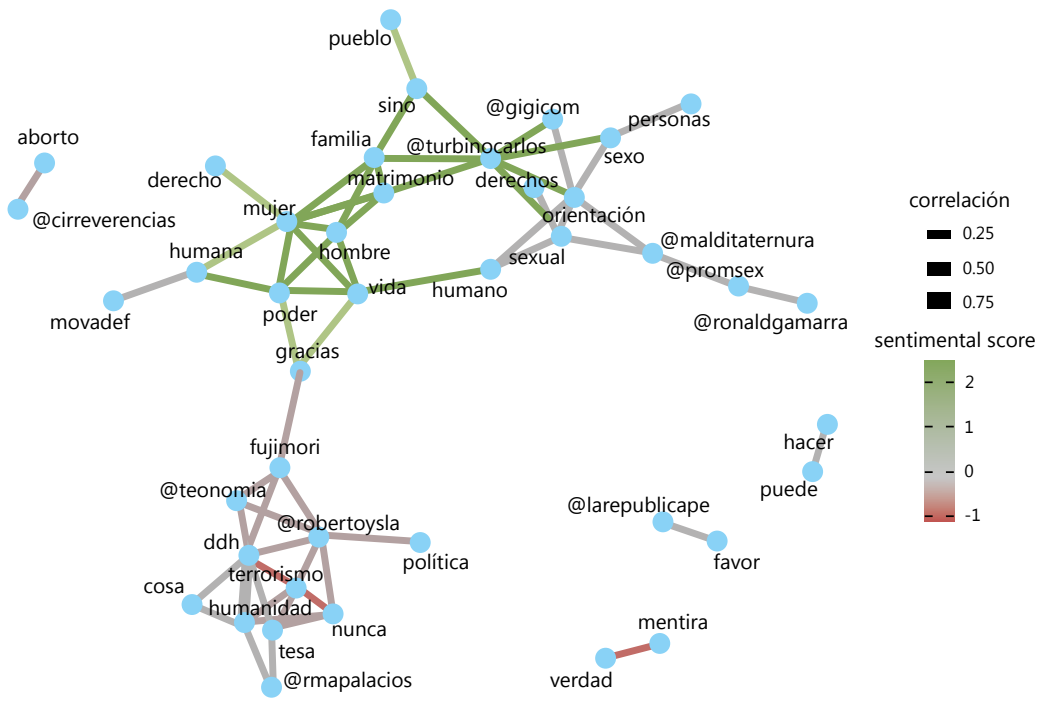

Nota: Incluye las palabras que verifican conjuntamente una correlación superior a 0,15 (enlaces) y alcanzan una frecuencia absoluta mínima de 20 entre los 1280 tuits (23/01/2011-26/02/2020) analizados de Christian Rosas. El grado de correlación se indica con el ancho de los enlaces y la puntuación media del sentimiento se indica con su color.

Fuente: Elaboración propia. 


\section{Palabras finales: más allá de la indignación}

Este artículo exploró una forma de activismo y de discurso que simultáneamente ataca al feminismo, al movimiento de la diversidad y a la izquierda. Dado su carácter multitemático y multidimensional, llamamos a este fenómeno interseccionalidad de derecha (ID). La ID aúna la retórica liberal de los derechos, la apelación conservadora a los valores familiares y religiosos y el lenguaje de la ciencia para impulsar una agenda política de extrema derecha. Estos diversos hilos discursivos se entretejen en un mismo nudo: la categoría síntesis de ideología de género (IG). Esta es una presencia constante en los planteos públicos de los personajes estudiados (figuras 1-3). La ID no es un fenómeno exclusivamente latinoamericano, pero los argumentos y las ideas que hemos analizado tienen un claro sabor regional.

Las características técnicas y los modelos comerciales de las redes sociales, Twitter entre ellas, facilitan la producción y difusión de la ID. La brevedad de los tuits, por ejemplo, estimula y premia la simplificación, el golpe de efecto y la violencia retórica. Mientras tanto, el uso de recursos visuales expande audiencias y también tiende a la priorización de la efectividad comunicacional por sobre la elaboración conceptual cuidadosa. En todo caso, parece que la extrema derecha hoy moviliza afectiva y efectivamente.

En contraste con la pesada jerga de la interseccionalidad (Robertson, 2017), la ID es didáctica, contundente y sencilla. El poder de la simplificación funciona como activo en un entorno cultural que rechaza la complejidad, la filosofía y los matices, y donde la tecnología, el desarrollo y la buena gestión son los nuevos mantras, incluso para una buena parte de las élites de izquierda. Sin embargo, puede especularse que la simplificación también genera limitaciones. ${ }^{24} \mathrm{~A}$ diferencia de lo que ha ocurrido en Norteamérica, donde personajes como Jordan Peterson le han otorgado densidad intelectual al pensamiento de derecha de hoy, en América Latina la ID carece de sofisticación y es académicamente marginal.

24 Como vimos, el Libro negro de la nueva izquierda presenta debilidades académicas que limitan su prestigio y probablemente su campo de acción. Entre éstas se cuentan faltas ortográficas, referencias a giros de $360^{\circ}$ (cuando se quiere decir 180), ausencia de prolijidad en el manejo de las fuentes, interpretación arbitraria de autores y fenómenos históricos, y apelación a extremos grotescos. Por ejemplo, se refiere a la "adopción sodomítica", con lo que se sugiere que los niños serán seguramente abusados por sus padres homosexuales (Laje y Márquez, 2017, p. 145). 
El estudio de la ID deja aprendizajes metodológicos y teóricos. En el primer plano, consideramos que la combinación de teoría crítica con diversas estrategias metodológicas, incluso aquellas que pueden ser categorizadas como convencionales o "cuantitativas", es rendidora y promisoria. En el plano teórico, la ID muestra que las llamadas divisiones no distributivas están lejos de ser una mera distracción del conflicto de clase. En el caso de la ID, son un componente fundamental de un proyecto reaccionario que es integrado y holístico. Esta innovación en el terreno de la política de derecha refleja la idea principal de la interseccionalidad, a saber: que el poder no se divide en los compartimentos de la economía política, la cultura, el género, etc. A pesar de echar mano a la simplificación, la ID encarna una comprensión pragmática e interesante de cómo funcionan el poder y la hegemonía. Además, el fenómeno de la ID reafirma la relevancia de las ideologías y las emociones en la política. Su capacidad para inspirar se explica en buena medida porque se anima a desafiar el establishment político liberal, y reclamar para sí el poder transformador y radical de la política.

Quizá la pregunta más acuciante es cómo responder a este fenómeno. Sin tratar de sustituir el saber específico de las y los activistas, queremos ofrecer un doble insight que nos parece que puede iluminar parte de este problema eminentemente político.

Por un lado, el odio y el ataque "le salen bien" a la extrema derecha. Competir con ella en esa senda es ética y estratégicamente estéril, si no peligroso y autodestructivo. Además, ningún activismo está exento del riesgo del dogmatismo y del autoritarismo y, por tanto, siempre está la posibilidad de volverse demasiado parecido a lo que se rechaza. Por el otro lado, tratar de convencer o "educar" argumentativamente a los representantes de la ID es en vano. Es inconveniente concurrir a una instancia de debate con ellos como si fueran simples interlocutores intelectuales. La ID está en guerra. Es muy probable que, luego del intercambio más o menos civilizado de ideas, aparezcan videos editados donde el intelectual conservador en cuestión "humilla a la feminista", "derrota al izquierdista", "ridiculiza al académico".

Detectamos así una tensión: parece necesario evitar caer en la trampa de la provocación, pero a la vez la indiferencia permite que estos discursos avancen y ocupen espacios. ¿Qué hacer entonces? En este artículo, optamos por objetivar el fenómeno, mostrar cómo funciona y desmantelarlo analíticamente. Esperamos que esto aporte, pero sabemos que es insuficiente. Las respuestas efectivas y constructivas solo pueden emerger de la colaboración entre diferentes perspectivas críticas de la academia y el activismo. Desde nuestro punto de vista, este fenó- 
meno político transnacional pone de manifiesto la necesidad de re-imaginar la política de izquierda más allá de la camisa de fuerza de los "derechos", los Estados nación y las instituciones liberales. Quizá el desafío de la ID se convierta en una oportunidad para tratarnos mejor, para generar solidaridades y afectuosidad entre diferentes esfuerzos emancipatorios y pasar del atrincheramiento tecnocrático a la ofensiva cultural y discursiva.

$\mathrm{Al}$ menos podemos asegurar esto: la interseccionalidad de derecha requiere una respuesta colectiva que trascienda la indignación.

\section{Referencias}

ACI Prensa. (2019, 20 de octubre). Agustín Laje, Nicolás Márquez y Patricia Sandoval reciben premio HazteOír. https://www.aciprensa.com/noticias/agustin-laje-nicolasmarquez-y-patricia-sandoval-reciben-premio-hazteoir-84886

Aguayo, G. y Rosas, C. (2019). Ideología de género: El nuevo intento por desnaturalizar el plan eterno de Dios. Peniel.

Aharony, N. (2012). Twitter use by three political leaders: An exploratory analysis. Online Information Review, 36(4), 587-603. https://doi.org/10.1108/14684521211254086

Anduiza, E., Cantijoch, M. y Gallego, A. (2009). Political participation and the Internet: A field essay. Information, Communication \& Society, 12(6), 860-878. https://doi. org/10.1080/13691180802282720

Aruguete, N. y Calvo, E. (2018). Time to\# protest: Selective exposure, cascading activation, and framing in social media. Journal of Communication, 68(3), 480-502. https://doi.org/10.1093/joc/jqy007

Ausserhofer, J. y Maireder, A. (2013). National politics on Twitter: Structures and topics of a networked public sphere. Information, Communication \& Society, 16(3), 291314. https://doi.org/10.1080/1369118X.2012.756050

BBC. (2021, 22 de octubre). Twitter's algorithm favours right-leaning politics, research finds. https://www.bbc.com/news/technology-59011271

Biroli, F. y Caminotti, M. (2020). The conservative backlash against gender in Latin America. Politics \& Gender, 16(1). https://doi.org/10.1017/S1743923X20000045

Cariboni, D. (2018, 1 de febrero). El género es el nuevo demonio. Revista Noticias. https://noticias.perfil.com/noticias/general/2019-02-01-el-genero-es-el-nuevodemonio.phtml

Carver, T. (2020). Interpretative methods. En Berg-Schlosser, D., Badie, B. \& Morlino, L. (Eds.). The SAGE Handbook of Political Science. Volumen 1 (pp. 406-422). London: SAGE.

Chagas, V., Modesto, M. y Magalhães, D. (2019). O Brasil vai virar Venezuela: Medo, memes e enquadramentos emocionais no WhatsApp pró-Bolsonaro. Esferas, 14, 1-15. http://dx.doi.org/10.31501/esf.v0i14.10374

Clare, E. (2017). Brilliant imperfection: Grappling with cure. Duke University Press. 
Cornejo-Valle, M. y Pichardo, J. I. (2017). La "ideología de género" frente a los derechos sexuales y reproductivos: El escenario español. Cadernos Pagu, 50, e175009. https:// doi.org/10.1590/18094449201700500009

Corredor, E. S. (2019). Unpacking "gender ideology" and the global right's antigender countermovement. Signs: Journal of Women in Culture and Society, 44(3), 613-638. https://doi.org/10.1086/701171

Crenshaw, K. (1989). Demarginalizing the intersection of race and sex: A black feminist critique of antidiscrimination doctrine, feminist theory, and antiracist politics. University of Chicago Legal Forum, 1989, 139-167.

Cupać, J. y Ebetürk, I. (2020). The personal is global political: The antifeminist backlash in the United Nations. The British Journal of Politics and International Relations, 22(4), 702-714. https://doi.org/10.1177/1369148120948733

DW. (2021, 11 de octubre). El anarcocapitalista Javier Milei agita la política argentina. https://www.dw.com/es/el-anarcocapitalista-javier-milei-agita-la-pol\%C3\%ADticaargentina/a-59462131

Eaton, K. (2014). New strategies of the Latin American right. Beyond parties and elections. En J. P. Luna y C. Rovira Kaltwasser (Eds.) The Resilience of the Latin American Right (75-93). Baltimore: Johns Hopkins University Press.

El Peluca Milei. (2021, 15 de junio). "Por primera vez los zurdos de mierda están perdiendo la batalla" - Milei con Canosa [video]. YouTube. https://www.youtube.com/ watch? $v=$ is $1 f 657 Z \times 70$

Gallego, C. y Romero, M. V. (2019). Sistematización del ataque al currículo nacional de educación básica. Centro de Promoción y Defensa de los Derechos Sexuales y Reproductivos. https://promsex.org/publicaciones/sistematizacion-del-ataque-alcurriculo-nacional-de-educacion-basica/

Geertz, C. (1997). La interpretación de las culturas. Gedisa.

Gerring, J. (2003). Interview with Clifford Geertz. Qualitative Methods, 1(2), 24-28.

Gioscia, L. y Wences, I. (2017). Sentir la política. Crítica contemporánea. Revista de Teoría Política, 7, 2-6. https://www.colibri.udelar.edu.uy/jspui/handle/20.500.12008/17579

Goldentul, A. y Saferstein E. (2020). Los jóvenes lectores de la derecha argentina: Un acercamiento etnográfico a los seguidores de Agustín Laje y Nicolás Márquez. Cuadernos del Centro de Estudios de Diseño y Comunicación, 24(112), 113-131. https:// doi.org/10.18682/cdc.vi112.4095

Gonzalez, L. (1988) Por um feminismo Afro-latino-americano. Tomado de: http://www. letras.ufmg.br/literafro/ensaistas/24-textos-das-autoras/1445-lelia-gonzalez-porum-feminismo-afro-latino-americano

Gramsci, A. (2008). Selections from the prison notebooks. International Publishers.

Gunnarsson, L. (2017). Why we keep separating the 'inseparable': Dialecticizing intersectionality. European Journal of Women's Studies, 24(2), 114-127. https://doi. org/10.1177/1350506815577114

Hawley, G. (2017). Making sense of the alt-right. Columbia University Press.

HazteOir.org. (2018, 7 de noviembre). Conferencia 'Marxismo, feminismo y LGTBI' con Agustín Laje y Nicolás Márquez [video]. YouTube. https://www.youtube.com/ watch?v=bOA5hblLHvs

Hill Collins, P. (1990). Black feminist thought: Knowledge, consciousness, and the politics of empowerment. Unwin Hyman. 
ISSI. (2018, 15 de marzo). George Hawley: Is the Alt-Right Collapsing? [video]. YouTube. https://www.youtube.com/watch?v=McqA5wmI5fQ

Kearney, M. W. (2019). rtweet: Collecting and analyzing Twitter data. Journal of Open Source Software, 4(42), 1829.

Laje, A. [@AgustinLaje]. (2019, 31 de octubre). Hermosa esta nota d los amigos d @ izquierdadiario, siempre tan ocupados en mí. Efectivamente: defiendo las 2 vidas, abomino de la ideología de género, reivindico nuestras gloriosas FFAA, apoyo la represión de los delincuentes y simpatizo con Bolso y Trump [tuit]. Twitter. https:// mobile.twitter.com/agustinlaje/status/1189860344522559489

Laje, A. (2021, 24 de octubre). Agustín Laje con Javier Milei: El terror de la casta política [video]. YouTube. https://www.youtube.com/watch?v=Q44RKIgMJcY

Laje, A. (2018, 23 de febrero). Ideología de género, nueva derecha, nueva izquierda [video]. YouTube. https://www.youtube.com/watch?v=Ir-3Ak_9KJO

La Nación. (2021, 13 de septiembre). "Excelente resultado". Tras ser la sorpresa de las elecciones, Javier Milei habló sobre una posible candidatura a presidente en 2023. https://www.lanacion.com.ar/politica/excelente-resultado-tras-ser-la-sorpresa-delas-elecciones-javier-milei-hablo-sobre-una-posible-nid13092021/

Losurdo, D. (2011). Liberalism: A counter-history. Verso Books.

Lugones, M. (2008). Colonialidad y género. Tabula Rasa, (9), 73-102.

Márquez, N. y Laje, A. (2017). El libro negro de la nueva izquierda: Ideología de género o subversión cultural. Pesur.

McCall, L. (2005). The complexity of intersectionality. Signs: Journal of Women in Culture and Society, 30(3), 1771-1800. https://doi.org/10.1086/426800

Mendos, L. R. (2020). Poniendo límites al engaño: Un estudio jurídico mundial sobre la regulación de las mal llamadas terapias de conversión. ILGA World. https://ilga.org/es/ terapias-conversion-estudio-juridicoponiendole-limites-engano\%E2\%80\%93ILGAWorld-febrero-2020

Menéndez-Carrión, A. (2015). Memorias de ciudadanía: Los avatares de una polis golpeada. La experiencia uruguaya. Fin de Siglo.

Meneses, D. (2019). Con mis hijos no te metas: Un estudio de discurso y poder en un grupo de Facebook peruano opuesto a la "ideología de género". Anthropologica, 37(42), 129-154. http://dx.doi.org/10.18800/anthropologica.201901.006

Mouffe, C. (2007). En torno a lo político. Fondo de Cultura Económica.

Mügge, L., Montoya, C., Emejulu, A. y Weldon, S. L. (2018). Intersectionality and the politics of knowledge production. European Journal of Politics and Gender, 1(1-2), 17-36. https://doi.org/10.1332/251510818X15272520831166

Nash, J. C. (2017). Intersectionality and its discontents. American Quarterly, 69(1), 117-129.

Ravecca Paulo, Marcela Schenck, Bruno Fonseca \& Diego Forteza (2022) What are they doing right? Tweeting right-wing intersectionality in Latin America, Globalizations, DOI: HYPERLINK "https://doi.org/10.1080/14747731.2021.2025292"10.1080/1474 7731.2021 .2025292

Pérez Bentancur, V. y Rocha-Carpiuc, C. (2020). The postreform stage: Understanding backlash against sexual policies in Latin America. Politics y Gender, 16(1), E3. https:// doi.org/10.1017/S1743923X20000069

Phoenix, A. y Pattynama, P. (2006). Intersectionality. European Journal of Women's Studies, 13(3), 187-192. https://doi.org/10.1177/1350506806065751 
Puar, J. (2007). Terrorist assemblages: Homonationalism in queer times. Duke University Press.

Ravecca, P. (2015). Our discipline and its politics: Authoritarian political science. Chile 1979-1989. Revista de Ciencia Política, 35(1), 145-178. https://doi.org/10.4067/ S0718-090X2015000100008

Ravecca, P. (2019). The politics of political science: Re-writing Latin American Experiences. Routledge.

Robertson, E. (2017, September 30th) Intersectional-what? Feminism's problem with jargon is that any idiot can pick it up and have a go. The Guardian: https://www. theguardian.com/world/2017/sep/30/intersectional-feminism-jargon

Rosas, C. [@xtian_rosas]. (2018, 21 de setiembre). En Argentina un grupo de activistas LGTBI olvidaron que la reproducción es una facultad exclusiva de los heterosexuales. La naturaleza les negó la posibilidad de reproducirse, defienden a hijos imaginarios de la misma forma que defienden su falsa identidad. \#ConMisHijosNoTeMetas https://t.co/Hi3oSZGEOp [tuit]. Twitter. https://twitter.com/xtian_rosas/ status/1043282660251119622

Rosas, C. [@xtian_rosas]. (2012, 8 de agosto) @RobertoYsla @teonomia El autoritarismo d Fujimori derroto al terrorismo avanzado c/ la menor cantidad d violaciones d DDHH del siglo pasado [tuit]. Twitter. https://twitter.com/xtian_rosas/status/233179211534331904

Rosas, C. [@xtian_rosas]. (2011, 22 de diciembre). @larepublica_pe Deberían influenciar ya que la defensa de la vida no es un tema religioso sino moral, es un asunto de DDHH [tuit]. Twitter. https://twitter.com/xtian_rosas/status/149841034698952704

Stolakis, K. (2020). Pray Away [documental]. Blumhouse Productions.

Tumasjan, A., Sprenger, T. O., Sandner, P. G. y Welpe, I. M. (2010). Predicting elections with Twitter: What 140 characters reveal about political sentiment. Proceedings of the Fourth International AAAI Conference on Weblogs and Social Media, 4(1), 178185. https://ojs.aaai.org/index.php/ICWSM/article/view/14009

Tumasjan, A., Sprenger, T. O., Sandner, P. G. y Welpe, I. M. (2011). Election forecasts with Twitter: How 140 characters reflect the political landscape. Social Science Computer Review, 29(4), 402-418. https://doi.org/10.1177/0894439310386557

Viveros Vigoya, M. (2016). La interseccionalidad: Una aproximación situada a la dominación. Debate Feminista, 52, 1-17. https://doi.org/10.1016/j.df.2016.09.005 


\section{Anexo metodológico: el análisis de los tuits}

Todas las cuentas y los tuits analizados eran públicos en el momento del estudio y se recogieron utilizando el paquete rtweet del software estadístico R cran (Kearney, 2019). Para cada cuenta, el límite máximo de tuits recogidos fue de 3200 , y se removieron los retuits para poder identificar y analizar material original. Esto explica las variaciones en el rango de tiempo y el número de tuits. Además, consideramos los tuits hasta el 26 de febrero de 2020 (cuando se reportó el primer caso de covid-19 en América Latina) para neutralizar el efecto masivo que la pandemia ha tenido sobre la opinión pública en la región.

Se realizaron dos tipos de análisis: un cálculo de coeficiente de correlación para los pares de palabras y un análisis del sentimiento de cada tuit. Para calcular las correlaciones entre palabras se utilizó el coeficiente phi. Este corresponde a la correlación de Pearson aplicada a dos variables binarias, por lo que su interpretación es similar. El coeficiente phi refleja la mayor probabilidad de que dos palabras aparezcan juntas, o no, en lugar de que una de ellas aparezca sin la otra:

$$
\varphi=\frac{\left(n_{00} n_{11}-n_{01} n_{10}\right)}{\sqrt{n_{1 . n_{0 .} n_{1} n_{.0}}}}
$$

\begin{tabular}{|c|c|c|c|}
\hline & $\mathbf{Y = 1}$ & $\mathbf{Y = 0}$ & Total \\
\hline $\mathbf{X = 1}$ & $n_{11}$ & $n_{10}$ & $n_{1 .}$ \\
\hline $\mathbf{X = 0}$ & $n_{01}$ & $n_{00}$ & $n_{0 .}$ \\
\hline Total & $n_{.1}$ & $n_{.0}$ & $n$ \\
\hline
\end{tabular}

Para el análisis del sentimiento utilizamos el enfoque de "bolsa de palabras", en el que cada tuit se considera una combinación de sus palabras individuales, por lo que se trata como un único documento. El sentimiento del tuit se calcula como la suma del sentimiento de las palabras que lo componen. El diccionario utilizado para el análisis fue el Léxico de Asociación Palabra-Emoción del NRC. Este léxico asigna a las palabras las siguientes emociones: ira, anticipación, asco, miedo, 
alegría, tristeza, sorpresa y confianza. Para este trabajo, solo se ha considerado la distinción más global entre sentimientos positivos y negativos.

Para visualizar conjuntamente la correlación y el sentimiento, hemos utilizado grafos. En estos, cada nodo representa una palabra y el ancho del enlace entre ellos refleja el coeficiente phi. Cada enlace está coloreado indicando la puntuación media del sentimiento de los tuits en los que las palabras conectadas aparecieron conjuntamente. Solo se graficaron los pares de palabras que registraron una correlación superior a 0,15 y que individualmente superaron un umbral de frecuencia absoluta (definido en función del número de tuits de cada cuenta).

El diccionario asigna sentimientos a palabras que son centrales en las narrativas analizadas y consideramos que esto podría añadir un sesgo. Por ejemplo, "aborto" tiene una connotación negativa y "presidente" o "familia", positiva. Para solucionar este problema, calculamos una puntuación de sentimiento ajustada eliminando los términos que aparecían en los grafos. No se identificaron diferencias significativas en los resultados, por lo que mostramos los gráficos utilizando el diccionario estándar. A lo largo de la investigación, hicimos un análisis de contenido cualitativo exhaustivo y detallado de los tuits. También estudiamos otras características e intervenciones de los actores seleccionados, tales como entrevistas, publicaciones en YouTube y artículos de prensa.

La figura 1 presenta el análisis de 22498 tuits de una muestra teórica de 17 influencers, activistas y políticos/as de Argentina, Chile, Colombia, Costa Rica, Ecuador, México, Paraguay, Perú, República Dominicana y Uruguay. Para obtener una visión general de toda la muestra, realizamos un gráfico en el que todos los individuos/cuentas en español están incluidos y tienen el mismo peso relativo. Para ello, replicamos mil veces un procedimiento en el que se muestrearon aleatoriamente 500 tuits para cada cuenta. En cada réplica, se calculó el análisis de sentimiento (puntuación de sentimiento y puntuación de sentimiento ajustada) y las correlaciones. Por último, la visión general se obtuvo considerando la media de todas las réplicas. Dado que las estadísticas se calcularon a partir de un conglomerado de cuentas diferentes, lo que hace menos probable obtener valores altos de asociación, el umbral de correlación considerado fue de 0,05. 